\title{
Organising a juvenile ratio monitoring programme for 10 key waterbird species in the Yangtze River floodplain: analysis and proposals
}

Yuxi Wang ${ }^{1}$, Iderbat Damba ${ }^{2,3,4}$, Qingshan Zhao ${ }^{2}$, Yanbo Xie ${ }^{5}$, Xueqing Deng ${ }^{2,3}$, Rdi Ga ${ }^{6}$, Guanhua Liu' Zhiwen $\mathrm{Xu}^{7}$, Yue Li ${ }^{8}$, Dali Gao ${ }^{9}$, Wenbin Xu' ${ }^{10}$, Guoxun Chen ${ }^{11}$ and Lei $\mathrm{CaO}^{2,3^{*}}$

\begin{abstract}
Background: In the face of continued degradation and loss of wetlands in the Yangtze River floodplain (YRF), there is an urgent need to monitor the abundance and distribution of wintering waterbirds. To understand fully observed annual changes, we need to monitor demographic rates to understand factors affecting global population size. Annual reproduction success contributes to dynamic changes in population size and age structure, so an assessment of the juvenile ratio (i.e. first winter birds as a proportion of total number aged) of overwintering waterbirds can be an important indicator of the reproductive success in the preceding breeding season.
\end{abstract}

Methods: During 2016-2019, we sampled juvenile ratios among 10 key waterbird species from the wetlands in the YRF. Based on these data, we here attempt to establish a simple, efficient, focused and reliable juvenile ratio monitoring scheme, to assess consistently and accurately relative annual breeding success and its contribution to the age structure among these waterbird species.

Results: We compared juvenile ratio data collected throughout the winter and found that the optimal time for undertaking these samples was in the early stages of arrival for migratory waterbirds reaching their wintering area (early to mid-December). We recommend counting consistently at key points (i.e. those where $>1 \%$ biogeographical flyway population were counted) at sites of major flyway importance (Poyang Lake, East Dongting Lake, Shengjin Lake, Caizi Lake, Longgan Lake and Chen Lake). Based on this, the error rate of the programme (155 planned points, the count of 10 waterbird species is $826-8955)$ is less than $5 \%$.

Conclusions: We established a juvenile ratio monitoring programme for 10 key waterbird species in the wetlands of the YRF, and discuss the feasibility and necessity of implementing such a future programme, and how to use these data in our monitoring and understanding of the population dynamics of these waterbird populations.

Keywords: Juvenile ratio, Monitoring scheme, The Yangtze River floodplain, Statistical independence

\footnotetext{
${ }^{*}$ Correspondence: leicao@rcees.ac.cn

${ }^{2}$ State Key Laboratory of Urban and Regional Ecology, Research

Center for Eco Environmental Sciences, Chinese Academy of Sciences, Beijing 100085, China

Full list of author information is available at the end of the article
}

\section{Background}

The Yangtze River stretches for $1893 \mathrm{~km}$, and drains an area of about $800,000 \mathrm{~km}^{2}$ (Ma 2014). The monsoon precipitation is concentrated mainly in summer, so water levels are highest in late summer but fall through winter (Nakayama and Shankman 2013). These periodic water original author(s) and the source, provide a link to the Creative Commons licence, and indicate if changes were made. The images or other third party material in this article are included in the article's Creative Commons licence, unless indicated otherwise in a credit line to the material. If material is not included in the article's Creative Commons licence and your intended use is not permitted by statutory regulation or exceeds the permitted use, you will need to obtain permission directly from the copyright holder. To view a copy of this licence, visit http://creativecommons.org/licenses/by/4.0/. The Creative Commons Public Domain Dedication waiver (http://creativeco mmons.org/publicdomain/zero/1.0/) applies to the data made available in this article, unless otherwise stated in a credit line to the data. 
level changes have created many seasonal wetlands, especially among the vast natural wetlands in the YRF, attracting 1,000,000 waterbirds to overwinter here from breeding areas further north (Barter et al. 2004, 2006). However, increasing water abstraction, pollution, aquaculture, overfishing, river traffic and other anthropogenic phenomena have caused habitat degradation and loss throughout the YRF, resulting in loss of biodiversity (Chen et al. 2017). As upper trophic level consumers, waterbirds are good indicators of many aspects of the ecosystems they live in. Hence, we need to monitor the distribution and abundance of waterbirds in the YRF, and also to assess the quality of their environment. To do this effectively, we need to understand their population dynamics that are driving their overall annual changes in abundance, which requires an understanding of their breeding success (annual gains to the overall population), balanced against mortality (as a measure of annual losses).

Waterbird abundance at a given wintering site may decrease because there has been a drop in the overall total population size since last winter, or because they have moved to better foraging site elsewhere (a fact which may indicate local habitat loss/degradation). It is therefore essential to obtain comprehensive simultaneous counts of waterbirds from throughout the flyway winter quarters to determine their abundance and distribution. In recent years, coordinated counts of wintering waterbirds throughout the YRF have brought China into line with a longer tradition of counts from Korea and Japan, which share several waterbird species in the Far East Asian flyway (Rees and Fox 2020). The analysis of these counts is the subject of a series of publications published as a special issue of the journal Wildfowl (Rees and Fox 2020), and their annual compilation enables us to determine changes in numbers at any given site in the context of changes elsewhere in the flyway.

While shifts in wintering distribution can give us insights into the effects of winter site quality on local abundance, population declines (which are likely manifest at all sites equally) requires explanation at the socalled "flyway" level. The concept of a waterbird flyway is a concept based on observed biological phenomena. Capture-mark-recapture studies throughout the world show waterbirds generally are highly site faithful to their breeding, staging and wintering sites (Schock et al. 2018). Recently, international collaboration has achieved extensive tagging of waterbirds throughout Far East Asia to follow their annual migrations (Rees and Fox 2020). This detailed information on movements of individuals throughout their annual cycle has enabled us to obtain a greater understanding of flyway structure. In this way, for example, it has been possible to show that there is no overlap in migration routes, staging areas and Arctic breeding grounds between the Bewick's Swans (Cygnus columbianus bewickii) that use Japan to winter and those individuals wintering in China (Fang et al. 2020). Similarly, Greater White-fronted Geese (Anser albifrons) wintering in Japan and Korea almost never overlap with individuals wintering in China during migration and on their Arctic breeding areas (Deng et al. 2020). This gives us some confidence in regarding these wintering groups as discrete entities ("biogeographical populations") in the sense that inter-annual differences in abundance are most affected by the balance between new recruits (first year birds) and the death of birds between successive winters, because their discreteness implies minimal immigration and emigration to and from these biogeographical populations. Insight into factors affecting the size of such populations requires an understanding of whether the causes of population decline is a reduction in annual reproductive success (Bromley and Rothe 2003) or annual survival (or a combination of both). Most large-bodied waterbirds are relatively long-lived and therefore sensitive to even small changes despite their relatively high annual survival rate (Johnson et al. 1992). Hence, an understanding of annual reproductive success can provide an insight into the causes for between-year fluctuations in winter abundance (for example, predator abundance cycles on Arctic breeding grounds; Nolet et al. 2013).

Plumage characteristics of most waterbirds enable us to distinguish between birds hatched in the preceding summer and those that are older (Baldassarre 2014). This provides an opportunity to distinguish, at very least, between first calendar year birds and older individuals in the autumn after reproduction in the northern hemisphere (Howes et al. 2019). As a result, there is a long tradition of assessing the relative reproductive success of populations by determining the juvenile ratios of waterbirds on their winter quarters. Such determinations are unable to determine the true reproductive output of a population, since many birds will have died or been lost from the population on the breeding areas or during migration. However, such juvenile ratios provide an assessment of the proportions of young that have returned to the winter quarters following the summer on the breeding quarters.

Most North American goose populations are monitored annually (U.S. Fish and Wildlife Service 2019). This is achieved within population-specific management plans for most identifiable goose populations, relying on monitoring data to support their conservation (Hestbeck et al. 1990; Cooch et al. 2001; Bromley and Rothe 2003). Hence, knowledge of juvenile ratios contributes greatly to our understanding of the causes of change in waterbird abundance (Johnson et al. 2018). Our knowledge of Far East Asian waterbird populations is very different from 
those in North America and Europe, but thanks to international cooperation throughout the flyway, this situation is improving rapidly. As outlined above, we are developing networks in China to annually census the numbers of overwintering species in the YRF, which are beginning to accumulate data over more than a decade. Our next challenge is to develop demographic monitoring systems to help us better understand trends in distribution and abundance, and central to this, we consider, is the compilation of juvenile ratio data from overwintering waterbird species in the YRF, which has rarely been reported to the present.

Before we embark on considerations about how to design a sampling programme for juvenile ratio assessment for deployment throughout the Yangtze, it is important to consider the experiences of others, which show that juvenile ratio samples vary in time and space (e.g. Ward et al. 2018). Telemetry has shown that nonbreeding or failed breeding geese moult and initiate autumn migration in Greater Snow Geese (Anser caerulescens atlantica) earlier than those successful breeders with broods (Reed et al. 2003), so samples undertaken too early (for example very in early winter, before the arrival of families) will underestimate juvenile ratios. Similar patterns have been confirmed for midcontinent Greater White-fronted Geese (Anser albifrons frontalis) at a northern autumn staging area (Schock et al. 2018). Waterbirds breeding at high latitudes also tend to arrive at wintering areas later than those that bred at low latitudes (Ely and Takekawa 1996; Ely et al. 2013). Again, early sampling may underestimate to contribution to overall population juvenile ratios of these elements of the population. Regular within-season changes in juvenile ratios are therefore something to be aware of (Lambeck 1990a), but for many goose species, moult also affects our ability to accurately assign individuals to age class. For instance, many grey geese of the genus Anser moult feathers in autumn and winter, which make juveniles more difficult to separate from adults with certainty from November onwards. The feeding profitability of habitats may also affect juvenile ratios. Large family groups among goose flocks are behaviourally dominant over small families, pairs and individuals (Boyd 1953) and so large families tend to feed in optimal foraging situations, which may segregate families and non-breeding birds between different habitats (Lambeck 1990b). This also explains the difference between the underrepresentation of first-winter Brent Geese (Branta bernicla bernicla) in samples taken from the leading edge of dense flocks and the underrepresentation of adults in the centres (Lambeck 1990a). Hence, it is important to consider an optimal timing and design sampling procedures. These considerations must be taken into account when thinking about how to best design our sampling programme for deployment throughout the Yangtze. This is especially important when considering the goals of the programme in relation to our understanding of the drivers of the population dynamics of each species and its age structure (Prevett and MacInnes 1980; Cowardin and Blohm 1992; Spaans et al. 1993; Alisauskas and Lindberg 2002).

Advances in our knowledge from the recent telemetry and count monitoring programmes have enabled us to define the flyway populations of waterbirds wintering in the Yangtze and assess their annual wintering distribution and abundance. On this basis, we considered it an essential next step to investigate the possibilities and potential problems associated with developing a sampling programme to monitor the reproductive output of a series of 10 key species for which we have accumulated wintering distribution and abundance. We selected Bewick's Swan, Swan Goose (Anser cygnoides), Lesser White-fronted Goose (Anser erythropus), Greater Whitefronted Goose, Greylag Goose (Anser anser), Bean Goose (Anser fabalis), Siberian Crane (Grus leucogeranus), Hooded Crane (Grus monachal), White-naped Crane (Grus vipio) and Common Crane (Grus grus). As a baseline, and to aid our programme design, we gathered juvenile ratio data on all these species throughout the YRF from 2016 to 2019, using the methods of Barter et al. (2004) to distinguish the species and to ensure a balanced consistent data-gathering regime in the field. In this paper, we analyse juvenile ratio data from these 4 years to attempt to understand the distribution and age structure of the 10 waterbird species wintering in these wetlands. Our aim here is to establish a simple, efficient and reliable juvenile ratio monitoring scheme for the future. The development of such a long-term monitoring scheme will enable a deeper understanding of the population dynamics of these species and provide the future scientific basis for the more effective management of these species.

\section{Methods \\ Data collection}

Data were collected twice a year from 2016 to 2019. The field surveys were conducted at 17 lakes in the YRF, an area that supports the highest density of shallow lakes in China (Qin et al. 2002). Detailed sampling sites and points are listed in Additional file 1: Table S1 (Point Distribution Map; see Fig. 1).

During the course of the 4 years of the juvenile ratio survey, we tried our best to ensure the consistent use of the same observation points at all of the lakes. However, some were rendered inaccessible due to construction work, changes in water level, the physical loss of some lakes and wetland habitats and other factors, all of which resulted in our inability to survey consistently 


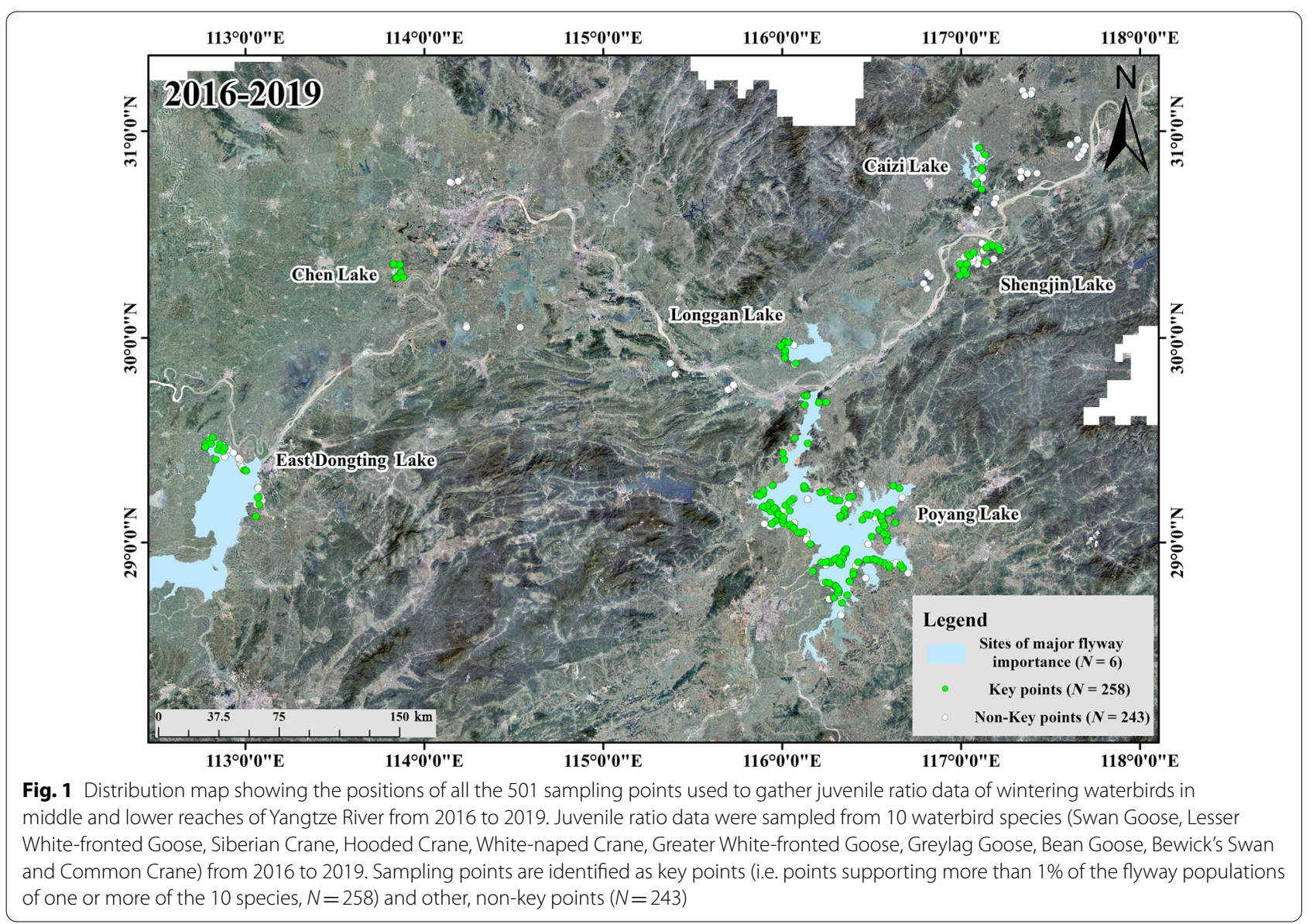

from designated observation points. In this case, we will replace the old points with new ones, so as to obtain similar coverage of the lake. On the other hand, based on the new information about previously unknown wintering areas of birds revealed by tracked individuals and suggestions of local reserve managers, we also added a few new points in some lakes in some years to obtain better data.

\section{Study team}

In order to minimise between-observer bias, all age determination work was led by one observer (Iderbat Damba) with considerable experience of waterbird plumages and age characteristics, supported by other observers with less experience. Field team compositions are listed in Additional file 1: Table S1. During each field survey, experienced observers used telescopes to detect individuals of all 10 species from a fixed viewing location and the total number of each species and the number of juveniles were counted (Gregory et al. 2004).

\section{Study species}

Our focal 10 large-bodied waterbird species included 5 endangered species (Swan Goose, Lesser White-fronted
Goose, Siberian Crane, Hooded Crane and White-naped Crane) and 5 non-endangered species (Greater Whitefronted Goose, Greylag Goose, Bean Goose, Bewick's Swan and Common Crane). Their wintering numbers in the YRF represents about $45 \%$ of the total number of waterbirds in the region (Barter et al. 2006). The morphological differences between the adults and the juveniles are shown in Additional file 1: Table S2.

\section{Timing of migration}

We used results from our ongoing telemetry tracking studies of the different species to judge the timing of migration to establish the duration of time when these 10 species are present in the YRF. This was important to judge when all of the birds have returned to their ultimate wintering grounds after completion of autumn migration. Full details of the duration of 8 species (Great White-fronted Goose, Swan Goose, Greylag Goose, Bean Goose, Lesser White-fronted Goose, Bewick's Swan, White-naped Crane, Siberian Crane) on the wintering grounds are shown in Additional file 1: Table S3 (Batbayar et al. 2013; Huang et al. 2018; Deng et al. 2019; Li et al. 2019, 2020a, b; Ao et al. 2020; Yang et al. 2020; Yi 
et al. in press). There are no representative satellite tracking results of the other 2 waterbird species considered here (Hooded Crane, Common Crane), but their autumn migration arrival phenology is similar to that of the other 8 waterbird species.

\section{Data analysis}

For each species, the overall annual juvenile ratio for each year was derived from the combined juvenile ratio determinations at all of the different lakes from which samples were taken in a given season (the sum of the juveniles/ the sum of the juveniles and adults). For those lakes for which only one survey was conducted in a given year, we took that juvenile ratio for these lakes as representative of that year. If two surveys were undertaken using the same observation points in the same year, we selected the larger sample of the two as representative of that lake in that year.

The programme aimed to derive extensive juvenile ratio data from all of the numerically most important discrete lakes for a given species during the 4-year investigation, lakes that also had the added advantage of being geographically dispersed. For this reason, we make the assumption that the juvenile ratio structure derived for each species in each of the 4 years reflects the true underlying juvenile ratios in the populations of these species on their wintering areas in those years. This assumption remains to be tested, but given the large sample sizes and their distribution from extensive sampling among large and small flocks from geographically dispersed lakes, we consider this a reasonable assumption to make.

To distinguish between sampling units, throughout this paper, we make the three definitions. The first is a "key site" as a lake where more than $1 \%$ biogeographical flyway population was counted, the second is a "key point" as a point where more than $1 \%$ biogeographical flyway population was counted and the last is a "site of major flyway importance" which is a lake that supports than $5 \%$ of total numbers of the defined population in that year. The $1 \%$ biogeographical flyway population of 10 waterbird species is shown in Additional file 1: Table S4 (Wetlands International 2021).

The juvenile ratio sample results from the 10 species of waterbirds from the 4 years are presented in the form of a mean and standard deviation. We denote the number of individuals of a given species sampled for age class as $N$, the number of juveniles as $n$, and the YRF sampled juvenile ratio of this species as $P=n / N$. At a given point $i$, we define the number of juveniles as $n_{i}$, the total sample aged is $N_{i}$, and the number of points covered within a lake is $K$. When considering only sites of major flyway importance, we calculated the percentage of data contributed by a given lake of a given species in that year as $\frac{\sum_{1}^{k} N_{i}}{N} \times 100 \%$, to illustrate the importance of the sites of major flyway importance, then the number of all sites of major flyway importance is $M=\sum K$. We defined the error rate of the juvenile ratio results of the survey in sites of major flyway importance as $\frac{\left|\left(\sum_{1}^{M} n_{i} / \sum_{1}^{M} N_{i}\right)-P\right|}{P} \times 100 \%$, and the error rate indicates the difference between the subsample value and the YRF sampled value for sites of major flyway importance.

If we define the number of key points in the sites of major importance as $O(O \leq M)$, the error rate of key points in the sites of major importance can be calculated as $\frac{\left|\left(\sum_{1}^{O} n_{i} / \sum_{1}^{O} N_{i}\right)-P\right|}{P} \times 100 \%$. The error rate reflects the difference between the theoretical value and the YRF sampled value when only the key points in sites of major importance are considered.

If we define the result of the previous investigation period as $P_{11}$ and the result from the subsequent period as $P_{12}$, then the error rate can be calculated as $\frac{\left|\left(P_{11}-P_{12}\right)\right|}{P} \times 100 \%$. In all statistical analyses, we used the comparisons of the mean $\pm \mathrm{SD}$ of the 4-year results to measure the changes between the annual results.

We constructed a mathematical model to calculate the theoretical size of the sample population needed to derive a robust estimate of YRF sampled juvenile ratio in the population as a whole. In the model, we approximate the field observation survey to the sampling, and assume that the number of young birds drawn in the sampling process is related to the juvenile ratio in the population as a whole, given that in the observation process, there are only two possibilities, of assigning birds as adult or young. In theory, when our observation times reach infinity, the $P$ value of observing young birds is equal to the juvenile ratio of the species throughout the year. After the actual $N$ counts, the mathematical expectation of this observation is $N P$, and the variance of this is $\sigma^{2}=N P(1-P)$. Meanwhile, due to errors in the observation itself, we believe that the number of young birds within the interval $N$ $(P-0.01)$ to $N(P+0.01)$ is consistent with the real situation after $N$ experiments, where 0.01 is the maximum allowable error value we assume, although the acceptable error value in the actual results is greater than our assumed value. After $N$ observations, because $N$ is generally large and can satisfy the conditions of $N P>5$ and $N(1-P)>5$, we can use the Gaussian distribution to estimate the result of this binomial distribution and select $E-\sigma<X<E+\sigma$. Therefore:

$$
\begin{aligned}
& E-\sigma=N(P-0.01) \\
& E+\sigma=N(P+0.01)
\end{aligned}
$$


(1) and (2) can be reformulated as:

$$
\begin{aligned}
& N P-\sqrt{N P(1-P)}=N(P-0.01) \\
& N P+\sqrt{N P(1-P)}=N(P+-0.01)
\end{aligned}
$$

Squaring (3) and (4) before reformulation gives:

$$
\begin{aligned}
& N P(1-P)=0.0001 \times N^{2} \\
& N=\frac{P(1-P)}{0.0001}
\end{aligned}
$$

Therefore, in order to ensure the accuracy of the investigation, $N=\frac{P(1-P)}{0.0001}$

This analysis assumes complete independence of observations in the investigation. However, in the real process, we cannot guarantee the complete independence of field observations, so it is necessary to design a scheme to measure the independence level of different species in field observation so that we can adjust the theoretical investigation value of $N$.

In order to measure independence, we still need to assume that the investigation process is independent, which means for each observation point, we need to obtain the difference value between the theoretical value and the actual value. By analysing the difference value, we will be able to obtain the independence of each species and correct $N$ according to these values. This requires the introduction of three extra variables as follows: $P$, the overall YRF sampled (actual) of encountering a young of a give species in a given year (i.e. the overall YRF sampled juvenile ratio of the species in that year); $N_{i}$, the total number of birds counted at the point $i$ of the species survey in that year and $P_{i}$, the probability of occurrence of juveniles at point $i$ of the species survey in the that year (i.e. the point sampled juvenile ratio at point $i$ of the species in the that year). We also introduce eight new parameters:

1. Expectation: defined as $\sqrt{\frac{P(1-P)}{N_{i}}}$, where $P$ is the overall YRF sampled juvenile ratio of the species in that year, and $N_{i}$ refers to the number of birds counted at this point $i$. It represents the theoretical error;

2. Error: defined as $\left(P_{i}-P\right)$, where $P$ is the YRF sampled juvenile ratio of the species in that year, $P_{i}$ refers to the juvenile ratio results at point $i$ of the species in that year. It represents true error;

3. Time: defined as Error/Expectation;

4. sqrt_Total: defined as $\sqrt{N_{i}}$, where $N_{i}$ refers to the number of birds counted at this point $i$;
5. Weight: defined as $\sqrt{N_{i}} / \sum \sqrt{N_{i}}$, where $N_{i}$ refers to the number of birds counted at this point $i$;

6. Time ${ }^{2}$ Weight: defined as Weight $\times$ Time $^{2}$;

7. sum_Weight: defined as $\sum$ (Weight $\times$ Time);

8. sqrt_sum_Weight: defined as $\sqrt{\sum\left(\text { Weight } \times \text { Time }^{2} \text { ). }\right.}$

Among these, Time ${ }^{2}$ Weight is used to measure the independence of survey points, while sqrt_sum_Weight is used to measure the independence of each year. In the revision process, since the value of $\sum$ (Weight) in each species survey is 1 , the theoretical population number in the actual survey needs to be revised to $\operatorname{Time}^{2} \times N$, but since we are conducting a long-term survey (Year $>8$ years), we believe that the theoretical population number in a single year survey can be revised to $\frac{\text { Time }^{2} \times N}{\text { Year }}$.

\section{Results}

\section{Juvenile ratio of 10 waterbird species in 2016-2019}

The overall annual juvenile ratios for each of the 10 species are shown in Table 1 and Additional file 1: Table S5. Across all species, 2017 was the year with lowest juvenile ratio, 2016 and the following two years were higher than 2017 (Table 1). The average juvenile ratio of 10 species was $0.169 \pm 0.031$, among which the juvenile ratios of Hooded Crane, White-naped Crane, Common Crane, Greylag Goose and Bewick's Swan were higher than the average, while the juvenile ratios of Siberian Crane, Swan Goose, Greater White-fronted Goose, Lesser Whitefronted Goose and Bean Goose were lower than the average.

Table 1 The overall annual juvenile ratio (expressed as proportion of first winter birds out of all birds aged) among 10 large-bodied waterbird species sampled in the Yangtze River Floodplain from 2016 to 2019

\begin{tabular}{llllll}
\hline Species & $\mathbf{2 0 1 6}$ & $\mathbf{2 0 1 7}$ & $\mathbf{2 0 1 8}$ & $\mathbf{2 0 1 9}$ & Mean \pm SD \\
\hline Common Crane & 0.187 & $\mathbf{0 . 1 3 5}$ & 0.184 & 0.241 & $0.187 \pm 0.037$ \\
Siberian Crane & 0.178 & $\mathbf{0 . 0 3 9}$ & 0.146 & 0.173 & $0.134 \pm 0.056$ \\
Hooded Crane & 0.257 & $\mathbf{0 . 1 6 9}$ & 0.231 & 0.252 & $0.227 \pm 0.035$ \\
White-naped Crane & 0.146 & $\mathbf{0 . 1 2 5}$ & 0.188 & 0.253 & $0.178 \pm 0.049$ \\
Swan Goose & 0.133 & $\mathbf{0 . 0 9 6}$ & 0.108 & 0.175 & $0.128 \pm 0.030$ \\
Lesser White-fronted & 0.344 & $\mathbf{0 . 0 6 0}$ & 0.090 & 0.113 & $0.152 \pm 0.112$ \\
Goose & & & & & \\
Greater White-fronted & 0.164 & $\mathbf{0 . 1 2 2}$ & 0.138 & 0.187 & $0.153 \pm 0.025$ \\
Goose & & & & & \\
Greylag Goose & 0.259 & $\mathbf{0 . 1 0 4}$ & 0.165 & 0.222 & $0.188 \pm 0.059$ \\
Bean Goose & 0.184 & $\mathbf{0 . 1 0 4}$ & 0.153 & 0.137 & $0.145 \pm 0.029$ \\
Bewick's Swan & 0.241 & $\mathbf{0 . 1 2 5}$ & 0.198 & 0.251 & $0.204 \pm 0.050$ \\
\hline
\end{tabular}

The values in bold represent the lowest juvenile ratio from all 4 years for each species, which for all species fell in 2017 
The basis for a Yangtze monitoring programme for the juvenile ratio of 10 waterbird species Rationalising cover of sites of major flyway importance

Based on the survey experience and results in 20162019, we have developed proposals for a monitoring programme to sample the juvenile ratio of 10 waterbird species in the future.

Compared with the surveys reported here, we would recommend reducing the number of lakes covered by future surveys, without loss of information. Based on the relative proportion of the 10 waterbird species that each lake held, we identified 6 lakes that meet the site of major flyway importance for the 10 waterbird species, namely Poyang Lake, East Dongting Lake, Shengjin Lake, Caizi Lake, Longgan Lake and Chen Lake (Additional file 1: Table S6). The distribution of waterbirds between the sites of major flyway importance was related to the habitat and feeding selectivity of different species. Of these, Poyang Lake played a vital role in providing the overwintering habitat of 9 waterbird species (45.9-100\%), excluding the Lesser White-fronted Goose which was almost totally confined to East Dongting Lake (>98\%).

When the samples derived from only the sites of major flyway importance in the monitoring programme, the overall error rate was under $5 \%$, which shows that our recommended plan for only sampling at sites of major flyway importance ( $N=6$ of the most important lakes) can robustly reflect the overall juvenile ratio results of each of the years from 17 lakes (Additional file 1: Table S7). On this basis, we only need to survey one third of the area covered in the full surveys to generate robust estimates of juvenile ratios for all 10 waterbird species.

\section{Rationalising cover of key observation points}

To further reduce sampling effort, we looked at possibilities to reduce the number of points necessary to generate robust juvenile ratio estimates.

We extracted all the observation points that meet the definition of key points from the sites of major flyway importance, and statistically re-analysed (see the distribution of observation points shown in Fig. 2). During the 4-year investigation period, the error rate of key points is shown in Additional file 1: Table S8. The overall error rate was about $5 \%$, which shows that our recommended plan for only sampling at key points of sites of major flyway importance ( $N=258$ of the most important points) can robustly reflect the overall juvenile ratio based on the results of all the years from 501 points (Additional file 1: Table S8). On this basis, we can generate robust estimates from only 258 observation points out of the original 501 points surveyed in the original work, a reduction in the extent of coverage of almost $50 \%$.

\section{Optimising the timing of the juvenile ratio survey}

As well as optimising the geographical extent of the field survey to maximise efficiency, it is important to determine the optimal time for undertaking the juvenile ratio surveys because of migration and turnover in the populations of waterbirds being sampled. During 2016 to 2019, two surveys were conducted in different survey periods within the same year and comparing these generated an overall error rate of $38.0 \% \pm 40.6 \%$ (Mean $\pm S D$, for full details see Additional file 1: Table S9) for the same species at the same lakes. This shows that differences in juvenile ratio results between different survey periods at the same lake are very large, so we cannot arbitrarily select a specific sampling period for monitoring juvenile ratios.

For this reason, we used data from satellite tracking studies of individuals from these wintering waterbird populations to provide the basis for the most effective timing for our monitoring programme. The telemetry results were shown in Additional file 1: Table S3. In summary, all of the eight species of waterbirds that we are concerned about here have completed their migration by early December. Given that the plumage characteristics of first winter birds change during the course of the winter as they moult (making it more difficult to reliably differentiate first winter from older birds), we recommend that observers start to undertake the juvenile ratio sampling in early to mid-December.

\section{Testing for statistical independence}

Our monitoring programme for juvenile ratio relies on field samples, while the effectiveness of the field investigation relies on its ability to reflect the underlying species population statistics and the effectiveness of identifying juveniles from adults. It is important to ensure the statistical independence of the sampling process and how this may affect the design of our juvenile ratio monitoring programme. In order to understand statistical independence, we have calculated the corresponding eight parameter results (see Additional file 1: Table S10).

Time $^{2}$ Weight is used to measure the independence of counts from a given point. When the counting process is a completely independent statistical process, sqrt_sum_Weight will be 1 in the overall YRF survey. So, the closer the sqrt_sum_Weight is to 1 for a given species, the stronger its statistical independence. Based on our results, the four species of crane (family Gruidae, sqrt_sum_Weight $=1.607)$, Siberian Crane, Hooded Crane, White-naped Crane and Common Crane showed the strongest independence. However, the other six 

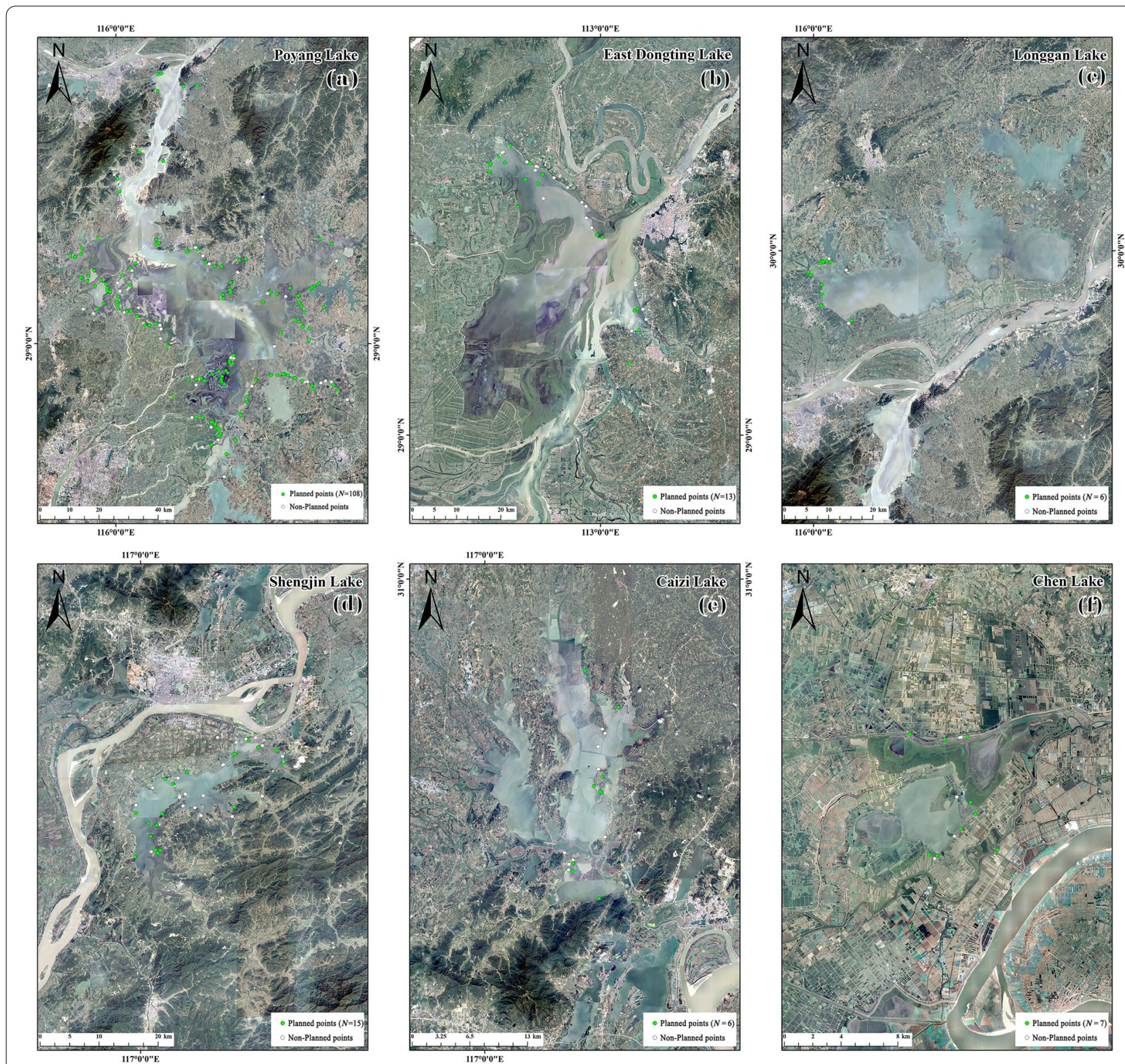

Fig. 2 Sites of major flyway importance for the 10 large-bodied waterbirds in the Yangtze River Floodplain. The map shows proposed sampling points for the future juvenile ratio field survey (green), all of which were located on key lakes (a Poyang Lake, $N=108 ; \mathbf{b}$ East Dongting Lake, $N=13$; c Longgan Lake, $N=6$; d Shengjin Lake, $N=15 ; \mathbf{e}$ Caizi Lake, $N=6 ; \mathbf{f}$ Chen Lake, $N=7)$. $N$ in each case is the number of planned points. Remaining points (shown in white) that were surveyed in 2016-2019 are not proposed to be sampled in the future unless circumstances change

species of waterbird (all Anatidae species, sqrt_sum Weight $=4.817$ ), Swan Goose, Lesser White-fronted Goose, Greylag Goose, Bean Goose, Greater Whitefronted goose and Bewick's Swan have weak independence (see Additional file 1: Table S11 for a complete breakdown of species by year).

\section{Establishing optimal species-specific sample size for the juvenile ratio surveys}

Assuming the statistical independence of the sampling process, we can calculate the theoretically optimal sample size for each species in each year to generate a robust juvenile ratio estimate (see "Methods" section for details), the results of which are shown in Table 2. The sqrt_sum_Weight values for the crane species 
Table 2 The optimal future survey sample sizes calculated based on analysis of the degree of statistical independence achieved for each of 10 large-bodied waterbird species in each year from 2016 to 2019

\begin{tabular}{|c|c|c|c|c|c|c|c|c|c|}
\hline \multirow[t]{2}{*}{ Species } & \multicolumn{2}{|l|}{2016} & \multicolumn{2}{|l|}{2017} & \multicolumn{2}{|l|}{2018} & \multicolumn{2}{|l|}{2019} & \multirow{2}{*}{$\begin{array}{l}\text { 2016-2019 } \\
\text { Optimal future } \\
\text { survey sample }\end{array}$} \\
\hline & Age ratio & $\begin{array}{l}\text { Survey } \\
\text { sample } \\
\text { (IH) }\end{array}$ & Age ratio & $\begin{array}{l}\text { Survey } \\
\text { sample } \\
\text { (IH) }\end{array}$ & Age ratio & $\begin{array}{l}\text { Survey } \\
\text { sample } \\
\text { (IH) }\end{array}$ & Age ratio & $\begin{array}{l}\text { Survey } \\
\text { sample } \\
\text { (IH) }\end{array}$ & \\
\hline Swan Goose & 0.133 & 1153 & 0.096 & 868 & 0.108 & 963 & 0.175 & 1444 & 2761 \\
\hline Lesser White-fronted Goose & 0.344 & 2257 & 0.060 & 564 & 0.090 & 819 & 0.113 & 1002 & 826 \\
\hline Siberian Crane & 0.178 & 1463 & 0.039 & 375 & 0.146 & 1247 & 0.173 & 1431 & 1129 \\
\hline Hooded Crane & 0.257 & 1909 & 0.169 & 1404 & 0.231 & 1776 & 0.252 & 1885 & 1744 \\
\hline White-naped Crane & 0.243 & 1839 & 0.125 & 1094 & 0.188 & 1527 & 0.253 & 1890 & 1588 \\
\hline Greater White-fronted Goose & 0.164 & 1371 & 0.122 & 1071 & 0.138 & 1190 & 0.187 & 1520 & 6364 \\
\hline Greylag Goose & 0.259 & 1919 & 0.104 & 900 & 0.170 & 1411 & 0.220 & 1716 & 1312 \\
\hline Bean Goose & 0.180 & 1476 & 0.104 & 900 & 0.150 & 1275 & 0.140 & 1204 & 8955 \\
\hline Bewick's Swan & 0.240 & 1824 & 0.125 & 1056 & 0.200 & 1600 & 0.250 & 1875 & 5844 \\
\hline Common Crane & 0.190 & 1539 & 0.135 & 1204 & 0.180 & 1476 & 0.240 & 1824 & 1511 \\
\hline
\end{tabular}

By then applying the overall sqrt_sum_Weight of each species (see "Methods" section, values derived from Additional file 1: Table S11), we can generate a value for the optimal future survey sample size to generate robust species juvenile ratios. IH means the independence hypothesis

varied between 0.7 and 2.7 , with many reasonably close to 1 , suggesting that these species attained a reasonable level of statistical independence, which suggest the recommended sample sizes were likely to be sufficient for the purposes of the survey. However, for the Anatidae species, sqrt_sum_Weight values varied between 1.1 and 13.3 (mean 4.817) which showed the level of statistical independence was not so good, necessitating the correction of the optimal theoretical sampling size using the sqrt_sum_Weight of each species. These optimal future survey sample sizes are shown for each species in Table 2, where the required samples for Bean Goose (8955) and Great White-fronted Goose (6364) can be seen to be more inflated than for the other species. In future, we need to check to ensure the recommended sample sizes for these species are maintained at a sufficient level in order to maintain the statistical independence of the sampling procedure.

\section{The monitoring programme for juvenile ratio of 10 waterbird species in the YRF}

Based on the above results, we obtained the 258 key points from the sites of major flyway importance from 2016 to 2019. For the purpose of future surveys (Table 3), we were able to reduce the 258 key points to 155 planned points for the 10 waterbird species based on the typical

Table 3 Final recommendations for the juvenile ratio sampling programme for 10 species of large-bodied waterbird species in the Yangtze River floodplain, by investigating their respective planned points based on the monitoring scheme

\begin{tabular}{|c|c|c|c|c|}
\hline Species & $\begin{array}{l}\text { Recommended } \\
\text { timing of the } \\
\text { surveys }\end{array}$ & $\begin{array}{l}\text { Recommended sites of major flyway } \\
\text { importance for each species to be } \\
\text { visited }\end{array}$ & $\begin{array}{l}\text { Recommended number of planned } \\
\text { observation points for each species }\end{array}$ & $\begin{array}{l}\text { Error } \\
\text { rate (\%) }\end{array}$ \\
\hline Swan Goose & $12 / 01-12 / 15$ & PYH, SJH & 26 & 0.82 \\
\hline Lesser White-fronted Goose & $12 / 01-12 / 15$ & DDTH & 7 & 4.17 \\
\hline Siberian Crane & $12 / 01-12 / 15$ & PYH & 19 & 1.58 \\
\hline Hooded Crane & $12 / 01-12 / 15$ & $\mathrm{PYH}, \mathrm{SJH}, \mathrm{CZH}$ & 19 & 1.20 \\
\hline White-naped Crane & $12 / 01-12 / 15$ & PYH & 21 & 0.50 \\
\hline Greater White-fronted Goose & $12 / 01-12 / 15$ & PYH, SJH, DDTH & 52 & 4.92 \\
\hline Greylag Goose & $12 / 01-12 / 15$ & $\mathrm{PYH}, \mathrm{LGH}, \mathrm{CH}$ & 15 & 1.77 \\
\hline Bean Goose & $12 / 01-12 / 15$ & PYH, SJH, DDTH, CZH & 59 & 1.24 \\
\hline Bewick's Swan & $12 / 01-12 / 15$ & PYH, LGH & 31 & 2.39 \\
\hline Common Crane & $12 / 01-12 / 15$ & PYH & 42 & 3.73 \\
\hline Total & $12 / 01-12 / 15$ & PYH, DDTH, SJH, LGH, CZH, CH & 155 & 2.23 \\
\hline
\end{tabular}

See "Methods" section for explanation for generating Error Rates

PYH Poyang Lake, DDTH East Dongting Lake, SJH Shengjin Lake, LGH Longgan Lake, CZH Caizi Lake, CH Chen Lake 


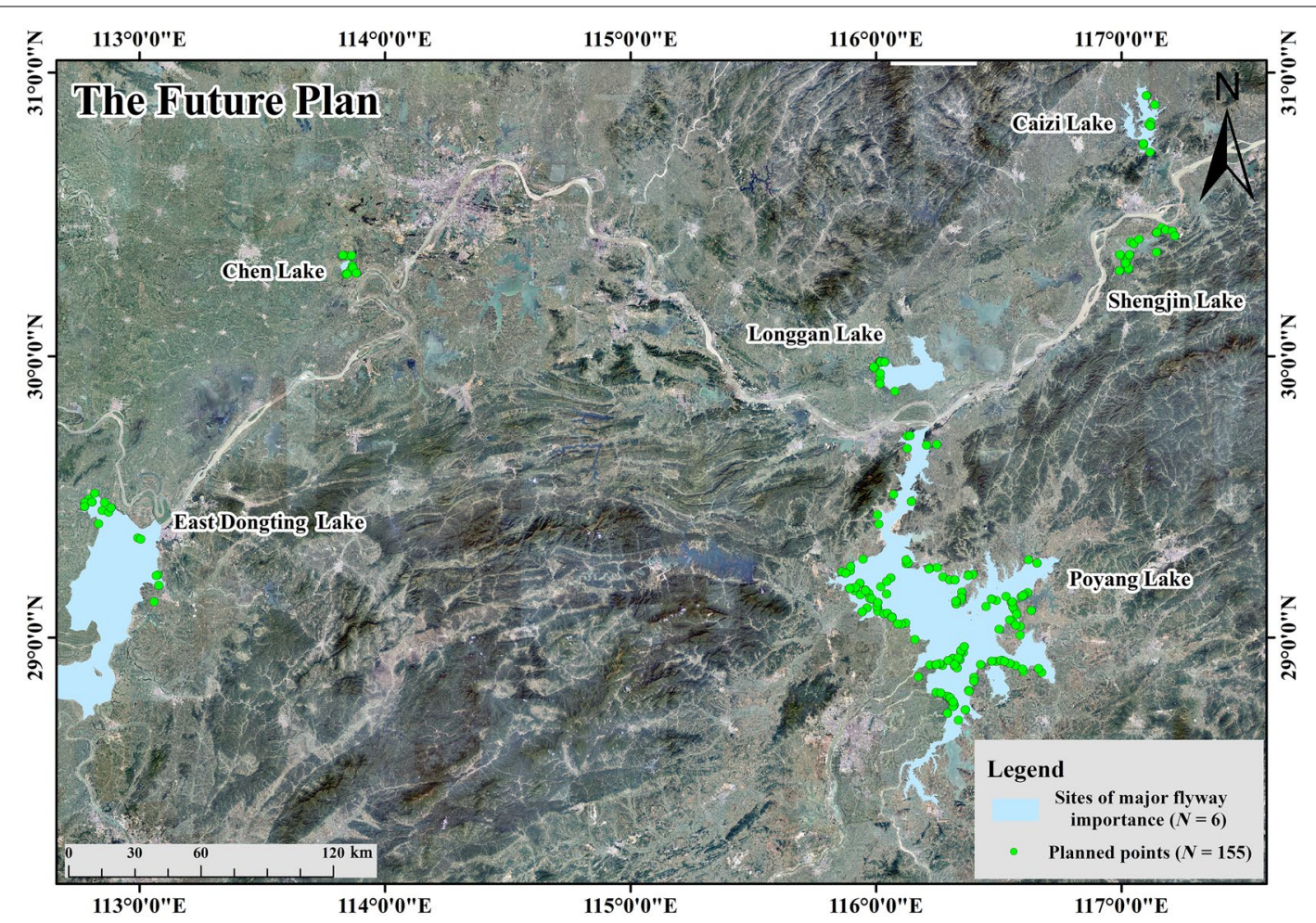

Fig. 3 The distribution map of the 155 proposed points for the future sampling of juvenile ratios among large-bodied waterbirds in the middle and lower reaches of the Yangtze River based on the results from analysis of data from the monitoring scheme. The proposed monitoring scheme will conduct juvenile age ratios among the 10 large-bodied waterbirds from early December to mid-December. The 155 planned points are confined to six sites of major flyway importance (Poyang Lake, East Dongting Lake, Shengjin Lake, Longgan Lake, Caizi Lake, Chen Lake)

observational range of a telescope $(2 \mathrm{~km})$. Based on these new recommendations, the predicted juvenile ratio of the investigation of sites of major flyway importance, key points and planned points (Fig. 3) and the theoretical juvenile ratio of the theoretical underlying populations does not differ substantially from the data generated from the entire survey (Additional file 1: Table S12). Compared with the effort required to achieve the level of survey coverage in 2016-2019, the new programme saves about $50 \%$ of the investigation time, reduces the workload in the investigation area by $66.7 \%$, and reduces the numbers of observation points to be visited by $48.3 \%$.

\section{Discussion}

A major contribution of the study to the effective management of this massive and globally important resource is to monitor the annual reproductive success of the waterbirds that use the Yangtze wetlands as winter quarters. This study has provided a statistically defensible means to organise a more concise, efficient, less timeconsuming, reliable sampling scheme for future researchers and managers for the first time based on the survey data and experience from sampling the juvenile ratios of
10 waterbird species over 4 winters. In this analysis, we show that it is feasible to sample in a statistically robust method, the juvenile ratios of 10 large-bodied waterbird species using a fraction of the effort expended in the original surveys. We show that we can reduce the time spent surveying and the number of observation points by a half (reducing the overall workload by two-thirds) without reduction in the statistical power of the survey results.

In the subsampling design for the future composition of the monitoring scheme, we will focus on coverage of the six most important lakes (Poyang, East Dongting, Shengjin, Longgan, Caizi and Chen Lakes), because these lakes support all the key observation points based on the last four winter surveys for the 10 waterbird species examined here. We would especially target Poyang Lake, which we have shown is extremely important for nine of the wintering waterbird species considered here, for intensive sampling of juvenile ratios. This is consistent with other studies that show many of the species considered here are increasingly concentrated within the YRF at Poyang Lake, making it of increasing significance for those species (Cao et al. 2008; Cao and Fox 2009). The results of this study point to sampling at other large lakes, 
such as East Dongting Lake, likely because their size accommodates birds that aggregate in large numbers, but also because larger lakes support a greater diversity of habitat types. This latter feature is important because the species considered here all differ in their diet and habitat use. For example, the Swan Goose forages for submerged tubers (An et al. 2018, 2019), Bean Goose grazes the above ground parts of Carex, as well as consuming grain seeds and plant buds (Yang et al. 2016), while the family Gruidae can prey on fish, crustaceans, invertebrates and other animals (BirdLife International 2017).

This also means that any sampling regime needs to account for the differential distribution of the 10 migratory waterbird species within and between the lakes, for which our approach has taken account. In the future, climate, hydrological and wetland land-use change, as well as human activity, will affect habitat distribution and quality in the YRF. This means that the habitat upon which waterbirds depend will change with time, which will bring challenges to the sustainability of our monitoring programme. While using the experience from earlier surveys to inform how best to undertake juvenile ratios in the future is inevitably based on a few recent years of experience, we also consider this approach does make the design future-proofed to some degree. Our recommendations for a future monitoring programme focus on the sites which are currently of major flyway importance, based on the current distribution and abundance of the 10 species. In order to take account of any changes in waterbird utilization of wetlands in the future, we would advocate maintaining our recommended programme, while reviewing our approach regularly based on the results from satellite tracking. In the face of habitat destruction and degradation, the waterbird juvenile ratio survey programme must be able to adapt sequentially to changes in the distribution and abundance of the 10 species within the YRF (Ydenberg and Prins 1981; Cromsigt et al. 2009; Heuermann et al. 2011). Should conditions change so much that birds start to redistribute outside of the YRF, the programme will need to address the change at larger spatial scales. This means that the programme need to communicate and cooperate with neighboring management units (such as Japan, South Korea and Russia, etc.) as well as in the YRF in monitoring, protection and data. At the same time, it will be essential to strengthen international cooperation in monitoring and protection in order to maintain and enhance waterbird and wetland protection in the future.

We see the programme we have initiated here as focusing on the YRF, but for a truly holistic species biogeographical flyway approach, we also need to extend the geographical scope outlined here. For instance, previous satellite tracking studies showed that potential Siberian
Crane habitat in the Yellow River Delta has not been visited on the ground or protected (Yang et al. 2020). If birds from the same biogeographical population are wintering outside the YRF, these should be incorporated into the programme if it is to be able to deliver robust juvenile ratio estimates for the entire population. Therefore, we strongly recommend that satellite tracking of these overwintering waterbird populations be extended as much as possible to improve on our current understanding of their wintering abundance and distribution to ensure the representativeness of our juvenile ratio sampling. By combining satellite tracking and monitoring programmes, we are confident that we can better monitor the distribution and age structure of these 10 waterbird species in the YRF, and support their effective conservation through better protection measures (de Boer et al. 2011; Pavón-Jordán et al. 2020).

\section{Conclusion}

Retrospective data analysis of the juvenile ratio data from 10 species of waterbirds sampled in 2016-2019 enabled us to see the degree to which a reduced set of lakes and samples from observation points could generate estimates that still reflected the overall juvenile ratios in the entire data set. Using this approach, we were able to recommend how to sample juvenile ratios in the future at much reduced effort without loss of statistical power. Because the 10 species of waterbirds are highly concentrated at relatively few sites of major flyway importance on their wintering areas, large samples (reflecting relatively high proportions of the entire wintering populations) could be sampled in this way. This was especially the case at Poyang Lake in Jiangxi Province, which has become of disproportionate importance in the YRF for many waterbird species. In addition, the results from the surveys suggested that the YRF sampled juvenile ratios of Swan Goose (VU), Lesser White-fronted Goose (VU) and Siberian Crane (CR) were lower than the average for all 10 species. This is especially alarming for the two goose species, because historical juvenile ratios and those from elsewhere in the range are thought to be higher and because their numbers are decreasing more than other species. This confirms the need for greater attention to be paid by researchers to understand factors affecting reproductive success and by protection and management personnel for the habitat and management needs of the species while on the winter quarters.

\section{Supplementary Information}

The online version contains supplementary material available at https://doi. org/10.1186/s40657-021-00309-x. 
Additional file 1: Table S1. The fieldwork that generated the data analysed here came from 17 lakes and 501 points in the YRF from 2016 to 2019. Table S2. Photographic information relating to the 10 waterbird species involved in the juvenile ratio survey of Yangtze River, illustrating the salient plumage differences and other features that are characteristic of adult and young birds of all species (Brazil 2009). Table S3. Autumn and spring migration schedules of eight large waterbird species in China based on published tracking studies. Table S4. The 1\% biogeographical flyway population levels for each of the 10 large-bodied waterbirds wintering in the Yangtze River Floodplain analysed here. Table S5. The sample sizes and juvenile ratio from each of the 10 large waterbird species surveyed in each year from 2016 to 2019 (see "Methods" - Data analysis). Table S6. The percentage of each large waterbird species counted in a given year at six sites of major flyway importance in the Yangtze River Floodplain. Table S7. The error rate between predicted juvenile ratio and YRF sampled juvenile ratio of 10 large-bodied waterbirds in Yangtze River Floodplain from 2016 to 2019. Table S8. The error rate between predicted juvenile ratio and Yangtze River Floodplain sampled juvenile ratio of 10 large-bodied waterbird species in sites of major flyway importance from 2016 to 2019. Table S9. The error rate between sampled juvenile ratio in November and sampled juvenile ratio in December of 10 large-bodied waterbirds in the same lake from 2016 to 2019. Table S10. The theoretical error, real error and T2_Weight results of 10 large-bodied waterbird species in the Yangtze River Floodplain based on statistical independence test analysis. Table S11. The sqrt_sum_Weight results of 10 large-bodied waterbird in YRF from 2016 to 2019 based on statistical independence test analysis. Table S12. Cross-comparison table showing juvenile ratios generated $(j / N$, where $j$ is the number of juveniles in sample $N$ ) from each annual sample (sample size $N$ ) for each of the 10 large-bodied waterbird species in each year, 2016 to 2019.

\section{Acknowledgements}

We are very grateful to the Professor Anthony David Fox of Department of Bioscience, Aarhus University, Denmark, who provided so much help with the structure and writing of the paper. We would sincerely like to thank all the volunteers, like Yuqing Han, Fujia Dong, Xiaoping Lu, Wenwen Niu, Taoping Wu and Itgelt, for their contributions to our field surveys. We would also like to thank the staff members of the Poyang Lake National Nature Reserve, the Nanji Wetland National Nature Reserve, Shengjin Lake National Nature Reserve, the Longgan Lake National Nature Reserve and the East Dongting Lake National Nature Reserve for their cooperation. Finally, thanks to all members of the investigation team responsible for the surveys of overwintering waterbirds in the Yangtze River.

\section{Authors' contributions}

$L C, Y W$ and $Y X$ conceived the ideas and designed methodology; ID, XD and RG collected the data; YW analyzed the data. YW led the writing of the manuscript, with contributions from LC. All authors contributed critically to the drafts. All authors read and approved the final manuscript.

\section{Funding}

Our study was supported by the National Natural Science Foundation of China (Grant Nos. 31870369, 31970433) and China Biodiversity Observation Networks (Sino BON). The funders had no role in study design, data collection and analysis, decision to publish, or preparation of the manuscript. Innovative Research Group Project of the National Natural Science Foundation of China (CN), No. 31670424.

\section{Availability of data and materials}

The datasets used in the present study are available from the corresponding author on reasonable request.

\section{Declarations}

\section{Ethics approval and consent to participate}

The following information was supplied relating to ethical approvals: Approval for bird counting in China was obtained from the Poyang Lake National Nature Reserve, the Nanji Wetland National Nature Reserve, Shengjin Lake
National Nature Reserve, the Longgan Lake National Nature Reserve and the East Dongting Lake National Nature Reserve.

\section{Consent for publication}

Not applicable.

\section{Competing interests}

The authors declare that they have no competing interests.

\section{Author details}

${ }^{1}$ School of Life Science, University of Science and Technology of China, Hefei 230026, China. ${ }^{2}$ State Key Laboratory of Urban and Regional Ecology, Research Center for Eco Environmental Sciences, Chinese Academy of Sciences, Beijing 100085, China. ${ }^{3}$ University of Chinese Academy of Sciences, Beijing 100049, China. ${ }^{4}$ Institute of Biology, Mongolian Academy of Sciences, Ulaanbaatar 13330, Mongolia. ${ }^{5}$ Department of Modern Physics, University of Science and Technology of China, Hefei 230026, China. ${ }^{6}$ College of Life Science and Technology, Inner Mongolia Normal University, Huhehaote 010000, China. ${ }^{7}$ Jiangxi Poyang Lake National Reserve Authority, Nan Chang 330038, China. ${ }^{8}$ Authority of Jiangxi Duchang Provincial Natural Reserve, Duchang 332600 , China. ${ }^{9}$ Authority of East Dongting Lake National Nature Reserve, Yueyang 414000, China. ${ }^{10}$ Anhui Shengjin Lake National Reserve Authority, Dongzhi 247000, China. ${ }^{11}$ Authority of Longgang Lake National Nature Reserve, Huanggang 435500, China.

Received: 26 February 2021 Accepted: 29 November 2021 Published online: 10 December 2021

\section{References}

Alisauskas RT, Lindberg MS. Effects of neckbands on survival and fidelity of white-fronted and Canada geese captured as non-breeding adults. J Appl Stat. 2002;29:521-37.

An A, Zhang Y, Cao L, Jia Q, Wang X. A potential distribution map of wintering Swan Goose (Anser cygnoides) in the middle and lower Yangtze River floodplain, China. Avian Res. 2018;9:1-10.

An A, Cao L, Jia Q, Wang X, Zhu Q, Zhang JJ, et al. Changing abundance and distribution of the wintering Swan Goose Anser cygnoides in the middle and lower Yangtze River floodplain: an investigation combining a field survey with satellite telemetry. Sustainability. 2019;11:1398.

Ao PR, Wang X, Solovyeva D, Meng FJ, Ikeuchi T, Shimada T, et al. Rapid decline of the geographically restricted and globally threatened Eastern Palearctic Lesser White-fronted Goose Anser erythropus. Wildfowl. 2020;9:206-43.

Baldassarre G. Ducks, geese, and swans of North America. New York: JHU Press; 2014.

Barter M, Chen L, Cao L, Lei G. Waterbird survey of the middle and lower Yangtze River floodplain in late January and early February 2004. Beijing: China Forestry Pulishing House; 2004.

Barter M, Lei G, Cao L. Waterbird survey of the middle and lower Yangtze River floodplain (February 2005). Beijing: World Wildlife Fund-China \& China Forestry Publishing House; 2006.

Batbayar N, Takekawa JY, Newman SH, Prosser DJ, Natsagdorj T, Xiao XM. Migration strategies of Swan Geese Anser cygnoides from northeast Mongolia. Wildfowl. 2013;61:90-109.

BirdLife International. BirdLife International and handbook of the birds of the world (2017) Bird species distribution maps of the world. 2017.

Boyd $\mathrm{H}$. On encounters between wild White-fronted Geese in winter flocks 1. Behaviour. 1953;5:85-128.

Brazil M. Birds of East Asia: China, Taiwan, Korea, Japan, and Russia. New York: A\&C Black; 2009.

Bromley RGH, Rothe TC. Conservation assessment for the dusky Canada goose (Branta canadensis occidentalis Baird). US Department of Agriculture, Forest Service, Pacific Northwest Research Station; 2003.

Cao L, Fox AD. Birds and people both depend on China's wetlands. Nature. 2009;460:173.

Cao L, Barter M, Lei G, Yang Q. Anatidae in the Yangtze floodplain in winter 2004 and 2005. Casarca. 2008;11:146-60.

Chen YS, Zhang SH, Huang DS, Li BL, Liu JG, Liu WJ, et al. The development of China's Yangtze River economic belt: how to make it in a green way. Sci Bull. 2017;62:648-51. 
Cooch E, Rockwell RF, Brault S. Retrospective analysis of demographic responses to environmental change: a lesser snow goose example. Ecol Monogr. 2001;71:377-400.

Cowardin LM, Blohm RJ. Breeding population inventories and measures of recruitment. In: Batt BDJ, Afton AD, Anderson MG, Ankney CD, Johnson DH, Kadlec JA, Krapu GL, editors. Ecology and management of breeding waterfowl. Minneapolis: University of Minnesota Press; 1992. p. 423-45.

Cromsigt JPGM, Prins HHT, Olff H. Habitat heterogeneity as a driver of ungulate diversity and distribution patterns: interaction of body mass and digestive strategy. Divers Distrib. 2009;15:513-22.

de Boer WF, Cao L, Barter M, Wang X, Sun MM, Oeveren H, et al. Comparing the community composition of European and Eastern Chinese waterbirds and the influence of human factors on the China waterbird community. Ambio. 2011:40:68-77.

Deng XQ, Zhao QS, Fang L, Xu ZG, Wang X, He HR, et al. Spring migration duration exceeds that of autumn migration in Far East Asian Greater White-fronted Geese (Anser albifrons). Avian Res. 2019;10:1-11.

Deng XQ, Zhao QS, Solovyeva D, Lee H, Harmey IB, Xu ZG, et al. Contrasting trends in two East Asian populations of the Greater White-fronted Goose Anser albifrons. Wildfowl. 2020;6:181-205.

Ely CR, Takekawa JY. Geographic variation in migratory behavior of Greater White-Fronted Geese (Anser albifrons). Auk. 1996;113:889-901.

Ely CR, Nieman DJ, Alisauskas RT, Schmutz JA, Hines JE. Geographic variation in migration chronology and winter distribution of midcontinent greater white-fronted geese. J Wildlife Manage. 2013;77:1182-91.

Fang L, Zhang JJ, Zhao QS, Solovyeva D, Vangeluwe D, Rozenfeld SB, et al. Two distinct flyways with different population trends of Bewick's Swan Cygnus columbianus bewickii in East Asia. Wildfowl. 2020;6:13-42.

Gregory RD, Gibbons DW, Donald PF. Bird census and survey techniques. Bird Ecol Conserv. 2004;17:56.

Hestbeck JB, Rusch DH, Malecki R. Estimating population parameters for geese from band-recovery and mark-recapture data. Trans N Am Wildlife Nat Resour Conf. 1990;350:73.

Heuermann N, van Langevelde F, van Wieren SE, Prins HHT. Increased searching and handling effort in tall swards lead to a Type IV functional response in small grazing herbivores. Oecologia. 2011;66:659-69.

Howes C, Symes CT, Byholm P. Highly skewed sex and juvenile ratios of European Honey Buzzard in southern Africa. J Ornithol. 2019;1:10.

Huang T, Xu XG, Peng J, Zhao YL. Study on migration route of wintering Bewick's Swan Cygnus columbianus in Dongting Lake based on satellite tracking. Sichuan Anim. 2018;37:361-72 (In Chinese).

Johnson DH, Nichols JD, Schwartz MD, et al. Population dynamics of breeding waterfowl. In: Batt DJ, Afton AD, Anderson MG, Ankney CD, Johnson DH, Kadlec JA, et al., editors. Ecology and management of breeding waterfowl. Minneapolis: University of Minnesota Press; 1992. p. 446-85.

Johnson FA, Alhainen M, Fox AD, Madsen J, Guillemain M. Making do with less: must sparse data preclude informed harvest strategies for European waterbirds? Ecol Appl. 2018;28:427-41.

Lambeck RHD. Differences in migratory pattern and habitat choice between social classes of the Brent Goose Branta bernicla bernicla. Ardea. 1990;78:426-40.

Lambeck RHD. The applicability of juvenile ratio and brood size counts in population dynamic studies of the Brent Goose Branta b. bernicla. Ardea. 1990;78:414-25

Li HB, Fang L, Wang X, Yi KP, Cao L, Fox AD. Does snowmelt constrain spring migration progression in sympatric wintering Arctic-nesting geese? Results from a Far East Asia telemetry study. Ibis. 2019;162:548-55.

Li XH, Wang X, Fang L, Batbayar N, Natsagdorj T, Davaasuren B, et al. Annual migratory patterns of Far East Greylag Geese (Anser anser rubrirostris) revealed by GPS tracking. Integr Zool. 2020;15:213-23.

Ma JH. Establishment of water resources support and guarantee for Yangtze River economic zone. Yangtze River. 2014;45:1-6 (In Chinese).

Nakayama T, Shankman D. Impact of the Three-Gorges Dam and water transfer project on Changjiang floods. Global Planet Change. 2013;100:38-50.

Nolet BA, Bauer S, Feige N, Kokorev YI, Popov BS, Ebbinge BS. Faltering lemming cycles reduce productivity and population size of a migratory Arctic goose species. J Anim Ecol. 2013;82:804-13.

Pavón-Jordán D, Abdou W, Azafzaf H, Balaž M, Bino T, Borg JJ, et al. Positive impacts of important bird and biodiversity areas on wintering waterbirds under changing temperatures throughout Europe and North Africa. Biol Conserv. 2020;246:108549.
Prevett JP, MacInnes CD. Family and other social groups in Snow Geese. Wildlife Monogr. 1980;71:3-46.

Qin BQ. Approaches to mechanisms and control of eutrophication of shallow lakes in the middle and lower reaches of the Yangze River. J Lake Sci. 2002;14:193-202.

Reed ET, Bêty J, Mainguy J, Gauthier G, Giroux JF. Molt migration in relation to breeding success in greater snow geese. Arctic. 2003;56:76-81.

Rees EC, Fox AD. Flyways, population trends and conservation challenges for the Anatidae in Far East Asia. Wildfowl. 2020;6:1-319.

Schock WG, Fischer JB, Ely CR, Stehn RA, Welker JM, Causey D. Variation in age ratio of midcontinent greater White-fronted Geese during fall migration. J Fish Wildl Manage. 2018;9:340-7.

Spaans B, Stock M, Joseph AS, Bergmann HH, Ebbinge BS. Breeding biology of dark-bellied brent geese Branta b. bernicla in Taimyr in 1990 in the absence of arctic foxes and under favourable weather conditions. Polar Res. 1993;12:117-30.

U.S. Fish and Wildlife Service. Waterfowl population status, 2019. U.S. Department of the Interior, Washington, D.C. 2019. https://www.fws.gov/migra torybirds/pdf/surveys-and-data/Population.

Ward DH, Amundson CL, Stehn RA, Dau CP. Long-term trends in fall juvenile ratios of black brant. J Wildlife Manage. 2018;82:362-73.

Wetlands International. Waterbird population estimates. 2021. wpe.wetlands. org. Accessed 13 Feb 2021.

Yang YZ, Zhan AB, Cao L, Meng FJ, Xu WB. Selection of a marker gene to construct a reference library for wetland plants, and the application of metabarcoding to analyse the diet of wintering herbivorous waterbirds. Peer J. 2016:4:e2345.

Yang $X L$, Jiang HX, Zou CL, Wang Y, Lin BQ, Li LS. Changes in migration pattern and important stopover sites of the eastern population of Siberian Cranes. For Sci. 2020;56:123-33 (In Chinese).

Ydenberg RC, Prins HHT. Spring grazing and the manipulation of food quality by barnacle geese. J Appl Ecol. 1981;18:443-53.

\footnotetext{
Ready to submit your research? Choose BMC and benefit from:

- fast, convenient online submission

- thorough peer review by experienced researchers in your field

- rapid publication on acceptance

- support for research data, including large and complex data types

- gold Open Access which fosters wider collaboration and increased citations

- maximum visibility for your research: over $100 \mathrm{M}$ website views per year
}

At BMC, research is always in progress.

Learn more biomedcentral.com/submissions 